\title{
The accessory artery in essential hypertension
}

\author{
Boon Seng OoI \\ M.B., M.R.A.C.P. \\ Lecturer in Clinical Medicine
}

\author{
SHENG FONG YU \\ M.B., D.M.R.D.
}

Consultant Radiologist, Department of Radiology

\author{
Beatrice T. M. Chen \\ M.B., M.R.A.C.P. \\ Senior Registrar in Clinical Medicine
}

OON TeIK KHOO

M.D., F.R.C.P.E.

Professor of Clinical Medicine

\section{Department of Clinical Medicine, University of Singapore and Department of Radiology, Outram Road General Hospital, Singapore}

\begin{abstract}
Summary
Ninety hypertensive patients were investigated by intravenous pyelography, abdominal aortography, and renal biopsy. Accessory arteries were present in four of thirty-nine patients with secondary hypertension, whereas sixteen of fifty-one patients with primary hypertension exhibited this anomaly.

These differences in distribution are statistically significant, and the relationship between accessory arteries and primary hypertension is discussed.
\end{abstract}

THE ASSOCIATION of multiple renal arteries with hypertension was first described by Marshall (1951). Robertson et al. $(1962,1967)$ have more recently emphasized this association, suggesting an aetiological link between renal arterial anomalies and essential hypertension. This view has however been challenged by Davies \& Sutton (1965) who could find no significant relationship between the two entities. The purpose of this communication is to provide further support for the thesis of Robertson and his colleagues.

\section{Materials and methods}

A prospective study of the causes of hypertension in patients under the age of 40 was started in 1966 and extended for 2 years. Hypertension was diagnosed when a diastolic blood pressure reading of $100 \mathrm{~mm} \mathrm{Hg}$ or more was obtained on two consecutive occasions. Ninety patients were investigated with intravenous pyelography and abdominal aortography. Thirty-three of these patients, in whom no obvious abnormality had been detected by radiographic means were subjected to renal biopsy. Abdominal aortography was performed by the technique of Seldinger (1953). No significant morbidity was encountered. The methods used, and the criteria used to differentiate primary and the various types of secondary hypertension have been previously described in detail (Ooi et al., 1970). (Essential hypertension was diagnosed when renal histology was normal or showed hypertensive vascular changes only.) Early aborization of a renal artery has not been included as an accessory artery, and the presence of multiple arteries in one patient has been listed only once.

\section{Results}

The full results of these investigations have been previously reported (Ooi et al., 1970).

Of the ninety patients investigated, a diagnosis of secondary hypertension was obtained in thirtynine patients $(43 \%)$. An accessory artery was present in sixteen of fifty-one $(31 \%)$ patients with primary hypertension whereas it was present in only four of thirty-nine $(10 \%)$ patients with secondary hypertension. The differences in distribution of the accessory artery in the two groups are statistically significant. $\left(\chi^{2}=4.55, P<0.05\right.$, applying Yates' correction.)

Renal biopsies have been done on four kidneys supplied by at least one accessory artery. Histological examination disclosed only hypertensive vascular changes. There was also no significant relationship between the presence of accessory arteries and pyelonephritis as determined by bacteriological, radiological or histological methods.

\section{Discussion}

The present study confirms the necropsy findings of Marshall (1951) and the more recent arteriographic observations of Robertson et al. (1962, 
1967). Robertson et al. (1962) investigating 121 patients, demonstrated the presence of multiple arteries in $70 \%$ of patients with primary hypertension compared with an incidence of only $40 \%$ in the secondary group. They have since studied a larger number of patients and obtained approximately the same results. (Robertson et al., 1967.) Davis \& Sutton (1965) analysing aortograms of 550 hypertensive patients could not demonstrate this difference. However, as subsequently pointed out by Robertson et al. (1965), Davies \& Sutton made no distinction between primary and secondary hypertension, and their objections are therefore not valid, since it is in the primary group of cases that the accessory artery has significance. Our series is particularly useful in this respect as the patients have been intensively investigated and a real attempt has been made to diagnose secondary hypertension. In fact, a finding of $43 \%$ of secondary hypertension in an unselected series compares favourably with results of other series-32\% (Breckenridge et al., 1967), 33\% (Robertson et al., 1967).

The significance of these observations is not clear. The persistence of multiple arteries represents persisting mesonephric arteries and is clearly a developmental anomaly. Robertson et al. (1967) have postulated on the basis of histologic observations that there is renal dysplasia associated with arterial anomalies. Nephrectomy specimens from some of their patients have disclosed histologic appearances of small hyaline glomeruli, abnormal tubules and lymphocytic infiltration. None of the four biopsy specimens obtained from our patients showed these abnormalities which in any case can result from ischaemia or chronic infection. Our observations also do not support their suggestion that there may be a significant relationship between infection and the presence of accessory arteries. In fact none of the patients with accessory arteries had bacteriuria or radiological pyelonephritis. It is certainly possible that the presence of accessory arteries could result in subtle microscopic or sub- microscopic renal circulatory disturbances leading to abnormalities in the juxta-glomerular vessels which could give rise to abnormalities in blood pressure regulation (Robertson et al., 1967). Whilst this possibility needs to be explored, it seems unlikely since even where there is macroscopic evidence of renal artery stenosis, there is an apparent lack of correlation between hypertension and renal artery stenosis (Schwart \& White, 1964). We are more inclined to Robertson's suggestion that a family history of hypertension may be related to an inherited pattern of arterial development. Certainly some of our patients with accessory arteries have a family history of hypertension but we have not done aortograms on patients above the age of 40 . Robertson and his colleagues have examples where arterial abnormalities are present in more than one member of the family.

\section{Acknowledgment}

We thank the radiologists of Outram Road General Hospital for their generous co-operation.

\section{References}

Breckenridge, A., Preger, L., Dollery, C.T. \& Laws, 兰 J.W. (1967) Hypertension in the young. Quarterly Journal of Medicine, 36, 549.

Davis, E.R. \& Sutron, D. (1965) Hypertension and multiple renal arteries. Lancet, $\mathbf{i}, 341$.

Marshall, A.G. (1951) Aberrant renal arteries and hype tension. Lancet, ii, 701.

OoI, B.S., Chen, B.T.M , Toн, C.C.S. \& Khoo, O.T. (1970) Causes of hypertension in the young. British Medical Journal, 3, 744.

Robertson, P.W., Klidjian, A., Hull, D.H., Hilton, D.D. \& Dyson, M.L. (1962) The assessment and treatment of hypertension. Lancet, ii, 567.

Robertson, P.W., Klidjian, A., Hull, D.H. \& Dyson, M.L Hypertension and multiple renal arteries. Lancet, i, 556.

Robertson, P.W., Hull, D.H., Klidjian, A. \& Dyson, M.L. (1967) Renal artery anomalies and hypertension. American Heart Journal, 73, 296.

Schwartz, C.J. \& WhITE, T.A. (1964) Stenosis of renal artery: An unselected necropsy study. British Medical Journal, 2, 1415.

Seldinger, S.I. (1953) Catheter replacement of the needle in percutaneous arteriography. Acta radiologica, 39, 368. 